\title{
Cutis plicata.
}

\author{
Von \\ Privatdozent Dr. Julius Heller, \\ Charlottenburg-Berlin.
}

(Hiezu Taf. II.)

Unter dem Namen Cutis plicata möchte ich eine Hautanomalie beschreiben, die, soweit meine Literaturkenntnis reicht, noch nicht zum Gegenstand einer Untersuchung gemacht ist.

Der P. ist ein kräftiger, 21 Jahre alter, seinen Jahren entsprechend aussehender Mann (Steinmetz), der wegen Herzbeschwerden Herrn Dr. Rehfisch, Berlin, aufgesucht hatte. Dr. R. erkannte sofort die Eigenart des dermatologischen Falles und überwies den P. mir. Sieht man von der Färbung und von der Konsistenz ab, so machte die Haut der beiden Hände, insbesondere der Handrücken den Findruck der Greisenhaut im höchsten Stadium der Altersatrophie. Dieser Ansicht wird man auch beim Anblick der Photographie, auf der die Farbe nicht zur Geltung kommt, beitreten. Die Falten entsprachen in ihrer Anordnung den im Greisenalter vorkommenden Falten; besonders charakteristisch sind die über dem Handgelenk quer über die Handwurzel, sowie die von den I. Fingerphalangen zum Handrücken ziehenden Falten. Die eigentlichen Handrücken zeigen unregelmäßige Faltensysteme; die Finger eine große Zahl von quer oder schief quer zur Längsachse verlaufenden Falten. Bei näherer Untersuchung unterscheidet sich aber der Prozeß ganz von der im Greisenalter vorkommenden Faltenbildung. Die ganze Haut ist gerötet; die Rötung ist keine so intensive, wie sie etwa bei der Erythromelie vorkommt, sondern entspricht mehr dem Grade der Färbung, die wie an der Haut kräftiger, an Arbeit in freier Luft gewöhnter Männerhände zu beobachten pflegen. Weit wichtiger ist die Konsistenz. Die Haut ist in toto hart; es gelingt weder durch Fingerdruck Dellen in ihr hervorzurufen noch sie im ganzen zu erheben und zu verschieben. Andrerseits ist die Härte nicht so beträchtlich wie etwa die bei der Sklerodermie beobachtete. Die Falten lassen sich weder durch seitlichen noch 
von oben hereinwirkenden Zug und Druck ausgleichen. Die Epidermis ist durchaus normal; keineswegs besteht die bei der Hautatrophie stets vorkommende Fältelung, die den bekannten Vergleich mit zerknittertem Zigarettenpapier herbeigeführt hat. Irgendwelche subjektiven Beschwerden machte die Hautveränderung nicht; der K. gab weder anormale Sensation noch Störungen bei der Funktion an. Es bestand nämlich starke Hyperidrosis. Der Versuch, durch Alkoholumschläge die Hautoberfläche zu entwässern hatte auf das hautklinische Bild keinen Einfluß.

Erwähnenswert ist die starke Erweiterung der Haarfollikel auf den Handrücken und vor allem auf die ersten Fingerphalangen, die wohl im Zusammenhang mit den veränderten Zugbedingungen bei der Cutis plicata stehen.

Von einer "Entwicklung" der "Krankheit" ist nicht die Rede. P. gibt mit Bestimmtheit an, daß er seit frübester Jugendzeit diese Hautveränderung gehabt habe. Eine weitere Beobachtung war mir nicht möglich, da der P. Berlin verlassen hat. Es konnte deshalb auch eine mikroskopische Untersuchung der Haut nicht vorgenommen werden.

Eine längere, epikritische Betrachtung des Falles erscheint ebenso überflüssig wie Hyposthesen über die Genese. Cutis laxa oder Idiopathische Hautatrophie (Typus Buchwald) ist ausgeschlossen; irgend ein Zusammenhang mit der Herzkrankheit ${ }^{1}$ ) (Ödeme, Stauungsanomalie) ist bei der nur auf die Handrücken beschränkten Affektion nicht annehmbar. Der neue Name: Cutis plicata soll nur das Charakteristische hervorheben. Hoffentlich werden weitere und exaktere Beobachtungen der Fachkollegen unsere Kenntnis auch über diese Hautveränderung bald erweitern.

Nach Fertigstellnng meiner Arbeit fand ich in den eben erschienenen Berichten des IX. Kongresses der Deutschen dermatologischen Gesellschaft einen von $\mathrm{J}_{\mathrm{ad}}$ as soh $\mathrm{n}$ berichteten Fall, der nach mancher Richtung mit dem von mir publizierten Ähnlichkeit hat. Bei einem Manne mittleren Alters war die nach Farbe und Konsistenz normale Kopf haut nicht glatt ausgespannt, sondern in unregelmäßige, $3 / 4-1^{1 / 2} \mathrm{~cm}$ breite Falten gelegt, die in den lateralen Partien mehr gerade von oben nach unten, in den zentralen mehr schräg und unregelmäßig verlaufen, auch mit einander anastomosieren und durch schmale tiefe Furchen scharf von einander getrennt sind. Palpatorisch erscheint die Haut verdickt; schiebt man die Haut seitlich zusammen, so kehrt sie langsam wieder in ihre ursprüngliche Lage zurück. Waelsch und Hochsinger haben ähnliche välle gesehen, Jadassohn hat noch eine analoge Beobachtung gemacht.

1) Es sei noch anhangsweise der von Herrn Dr, Reh fi sch gütigst zur Verfügung gestellte Herzbefund gegeben: "Cor klein, $10 \mathrm{~cm}$ breit; linke Herzgreaze $2.5 \mathrm{~cm}$ inframamillär. Spitzenstoß im 5 . Interkostalraum, stark hebend; über der Pulmonalis (nicht über der Aorata) systoliches Geräusch. Herztöne rein. Arteria radialis, weich, gut gespannt. R. nimmt keine Pulmonalstenose an, sondern hält das fragliche Geräusch für ein Lungengeräusch. 


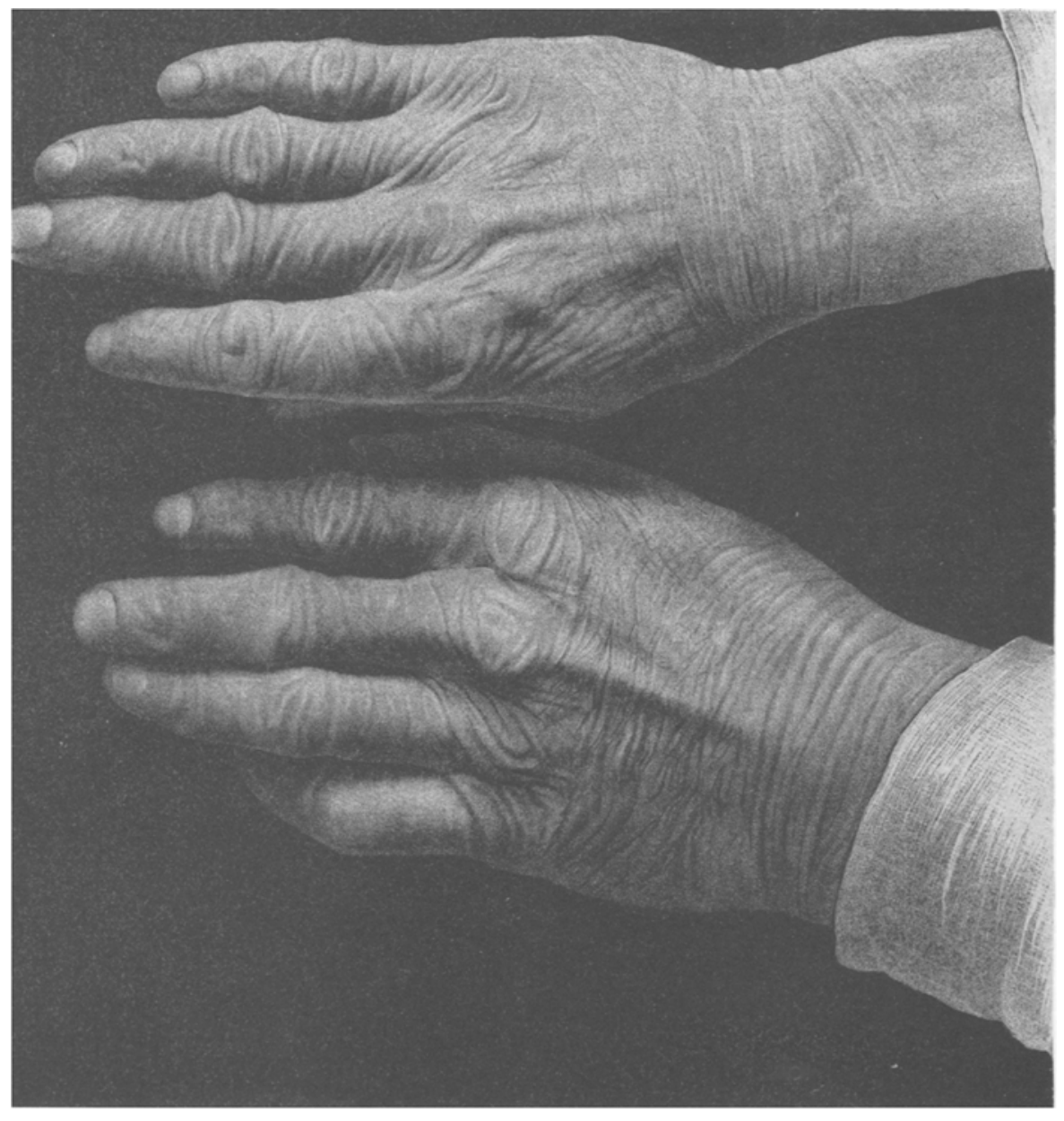

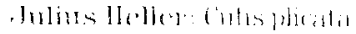

